\title{
Balanço Eletrolítico e Níveis de Proteína Bruta sobre o Desempenho, o Rendimento de Carcaça e a Umidade da Cama de Frangos de Corte de 1 a 42 dias de Idade ${ }^{1}$
}

\section{Flávio Medeiros Vieites ${ }^{2}$, George Henrique Kling de Moraes $^{3}$, Luiz Fernando Teixeira Albino ${ }^{4}$, Horacio Santiago Rostagno ${ }^{4}$, Anel Atencio ${ }^{5}$, José Geraldo de Vargas Junior ${ }^{6}$}

\begin{abstract}
RESUMO - Foi realizado um experimento com o objetivo de determinar os melhores valores de balanço eletrolítico (BE) para frangos de corte de 1 a 42 dias de idade. Na fase inicial, utilizaram-se 2.112 pintinhos machos da linhagem comercial Ross, criados em boxes de galpão de alvenaria cobertos com maravalha e alimentados com duas rações basais, uma com 20 e outra com $23 \%$ de proteína bruta (PB) à base de milho e de farelo de soja, combinadas com níveis de $\mathrm{BE}$ de $0 ; 50 ; 100 ; 150 ; 200 ; 250 ; 300$ e $350 \mathrm{mq} / \mathrm{kg}$. Na fase de crescimento, utilizaram-se 1.728 frangos oriundos da fase inicial e apenas uma ração basal com $20 \%$ de PB. Foi utilizado delineamento experimental inteiramente casualizado, em esquema fatorial 8 × 2 (oito níveis de BE e duas seqüências protéicas), seis repetições e 18 aves por unidade experimental na fase de crescimento. Avaliaram-se o ganho de peso (GP), o consumo de ração (CR), a conversão alimentar (CA), o rendimento de carcaça, os cortes nobres e a matéria seca na cama das aves aos 42 dias de idade. Os melhores valores de BE estimados foram 179 (20-20\% PB) e 185 (23-20\% PB) mEq/kg e valores similares foram encontrados para os maiores CR, 193 (20-20\% PB) e 192 (23$20 \% \mathrm{~PB}) \mathrm{mEq} / \mathrm{kg}$. A CA teve como melhor valor estimado $159(23-20 \%) \mathrm{mEq} / \mathrm{kg}$, um pouco abaixo dos valores de BE obtidos para GP e CR. Para o rendimento de carcaça e de cortes nobres, os melhores valores de BE foram similares aos de desempenho. Os valores de BE obtidos para os maiores teores de matéria seca na cama das aves foram 138 (20-20\%) e 148 (23-20\%) mEq/kg. Considerando-se os dados obtidos, recomenda-se um valor de BE na faixa de 160 a $190 \mathrm{mEq} / \mathrm{kg}$ como ótimo para frangos de corte de 1 a 42 dias de idade.
\end{abstract}

Palavras-chave: frangos de corte, equilíbrio ácido-básico, desempenho, teor protéico, cortes nobres, cama de frango

\section{Effects of Electrolyte Balance and Crude Protein Levels on Performance, Carcass Yield and Broiler Litter of Broiler from 1 to 42 Days Old}

\begin{abstract}
An trial was conducted to determine the best electrolyte balance (EB) for broilers from 1 to 42 days old. In the first phase of the experiment 2,112 Ross chicks male were reared in the floor covered with shaving woods and fed two corn-soybean meal based diet: one with 20 and one with $23 \%$ of crude protein (CP) combined with $0 ; 50 ; 100 ; 150 ; 200 ; 250 ; 300$ and $350 \mathrm{mEq} / \mathrm{kg}$ of EB. In the growing phase, 1,728 broilers of the total, remained in the experimental units and were fed only a basal diet. The experiment was analyzed as a completely randomized design with a factorial arrangement of treatments (two protein sequences and eight EB levels) and six replicates of 18 broilers each one. The following parameters were evaluated: weigh gain (WG), feed consumption (FC), feed efficiency (FE), carcass yield, noble cuts and the dry matter of broiler litter at 42 days of age. The best EB estimated at 42 days were 179 (20-20\% CP) and 185 (23-20\% $\mathrm{CP}) \mathrm{mEq} / \mathrm{kg}$ for the WG and similar values were found for the highest FC, $193(20-20 \% \mathrm{CP})$ and $192(23-20 \% \mathrm{CP}) \mathrm{mEq} / \mathrm{kg}$. The FE (23$20 \% \mathrm{CP}$ ) had the best value estimated $159 \mathrm{mEq} / \mathrm{kg}$, lower than the values found for WG and FC. For carcass yield and noble cuts the best values obtained were similar to the performance values. The values obtained for the highest level of dry matter in the broiler litter were 138 $(20-20 \% \mathrm{CP})$ and $148(23-20 \% \mathrm{CP}) \mathrm{mEq} / \mathrm{kg}$. Based on the obtained data, EB should be from 160 to $190 \mathrm{mEq} / \mathrm{kg}$ for the best performance of broilers from 1 to 42 days old.
\end{abstract}

Key Words: broilers, acid basic balance, performance, protein level, noble cuts, broiler litter

\section{Introdução}

Os eletrólitos da ração consumida pelos animais exercem influência no equilíbrio ácido-básico e, conseqüentemente, afetam processos metabólicos relacionados ao crescimento, à resistência a doenças, à sobrevivência ao estresse e aos parâmetros de desempenho.
Mongin (1981) estudou os fundamentos do balanço eletrolítico (BE) para aves e suínos e concluiu que pode-se descrever o equilíbrio entre os íons por um cálculo envolvendo os principais deles, cuja fórmula representativa é o resultado da soma dos íons $\mathrm{Na}^{+}$e $\mathrm{K}^{+}$, subtraindo-se o íon negativo $\mathrm{Cl}^{-}$, denominado $\mathrm{BE}$.

\footnotetext{
1 Parte da tese de Doutorado apresentada pelo primeiro autor à UFV

${ }^{2}$ Médico Veterinário, DSc em Nutrição de Monogástricos. E.mail: fmvieites@yahoo.com.br

3 Professor do DBB/UFV, Campus Universitário - Viçosa MG, Brasil CEP 36571-000.

4 Professor do DZO/UFV, Campus Universitário - Viçosa MG, Brasil CEP 36571-000.

${ }^{5}$ Médico Veterinário, DSc em Nutrição de Monogástricos. E.mail: anel@arches.uga.edu

6 Zootecnista, DSc em Nutrição de Monogástricos. E.mail: jgvargas@bol.com.br
} 
O balanço cátion - ânion altera o equilíbrio ácidobásico, indicado pelo $\mathrm{pH}$ e pelas concentrações de bicarbonato no sangue. Dietas aniônicas, ricas em cloretos, sulfatos e fósforo tendem causar acidemia, enquanto dietas enriquecidas com sódio e potássio tendem a causar alcalemia (Johnson \& Karunajeewa, 1985; Halley et al., 1987).

Segundo Murakami (2000), tem-se recomendado BE entre 150 e $350 \mathrm{mEq} / \mathrm{kg}$ de ração, em dietas comerciais, para o máximo desempenho das aves. Leeson \& Summers (2001) consideram $250 \mathrm{mEq} / \mathrm{kg}$ como valor adequado para o bom desenvolvimento das aves.

Em muitos estudos, os critérios para avaliar a exigência adequada dos nutrientes na produção comercial de aves são a taxa de crescimento e a eficiência alimentar. Entretanto, cada vez mais a indústria avícola tem buscado o rendimento e a composição da carcaça de aves que apresentem melhor rendimento de cortes nobres (peito e coxa). As empresas avícolas brasileiras estão procurando inserir na filosofia de trabalho os programas de qualidade total e a certificação ISO 9000, visando padronizar, qualificar e, conseqüentemente, agregar valores aos seus produtos.

Os eletrólitos também são responsáveis pelo maior aumento de umidade nas fezes das aves. Casado \& Virseda (1983), ao suplementarem rações de aves de recria com $\mathrm{Na} \mathrm{e} \mathrm{K}^{-1}$, concluíram que ambos promovem aumento da excreção de água. Com isso, as aves podem ficar mais susceptíveis a doenças e apresentarem queda em seu desempenho produtivo, além de favorecerem o aumento da umidade da cama.

Objetivou-se, com este trabalho, determinar o melhor valor de BE em dois níveis (20 e 23\%) de proteína bruta (PB) sobre o desempenho e rendimento de carcaça e cortes nobres de aves de corte de 1 a 42 dias de idade e avaliar a umidade de cama dos frangos.

\section{Material e Métodos}

O experimento foi conduzido no setor de avicultura do Departamento de Zootecnia da Universidade Federal de Viçosa, no período de outubro a novembro de 2001. O abate das aves foi feito no abatedouro da UFV e a análise de cama no Laboratório de Nutrição Animal do Departamento de Zootecnia da UFV.

O período experimental compreendeu as fases inicial ( 1 a 21 dias) e de crescimento ( 22 a 42 dias). $\mathrm{Na}$ fase inicial, utilizaram-se 2.112 pintinhos machos da linhagem comercial Ross e duas rações basais (20 e
$23 \%$ de $\mathrm{PB}$ ). Na fase de crescimento, foram utilizados 1.728 frangos oriundos da fase inicial e apenas uma ração basal (20\% de PB), corrigindo-se o desempenho em função da mortalidade dos animais até os 42 dias.

As aves foram alojadas em galpão de alvenaria, com pé direito de 3,0 $\mathrm{m}$ de altura, cobertura com telhas de cimento amianto, provido de lanternim, mureta com laterais de $0,50 \mathrm{~m}$ e tela de $1 / 2$ ', Foram utilizados boxes de $1,25 \times 1,80 \mathrm{~m}\left(2,25 \mathrm{~m}^{2}\right)$ com piso de cimento. No piso de cada boxe, foi colocada maravalha como cama (altura de $10 \mathrm{~cm}$ ).

Durante o período experimental, foi adotado programa de luz contínuo (24 horas de luz natural + artificial). Para aquecimento dos pintos, do $1^{\circ}$ ao $15^{\circ}$ dia, foram utilizadas lâmpadas de infravermelho de $250 \mathrm{~W} /$ boxe, com altura regulável.

A temperatura e a umidade relativa do ar foram medidas com termômetros de máxima e mínima, de bulbos seco e úmido e termômetro de globo negro, para obtenção do ITGU (Índice de Temperatura de Globo e Umidade). A temperatura do galpão foi registrada diariamente e as leituras foram feitas às 7 e às $19 \mathrm{~h}$ por meio de termômetros de máxima e mínima, obtendo-se médias de 21 e $29^{\circ} \mathrm{C}$ das temperaturas máximas e mínimas, respectivamente, para o período experimental. As leituras dos termômetros das demais variáveis foram realizadas cinco vezes ao dia $(7,10,13,16$ e 19 h) e suas médias corresponderam a $73 \%$ para a umidade relativa do ar e 74 para o ITGU.

No período de 1 a 21 dias de idade, as aves receberam rações à base de milho, farelo de soja e glúten de milho, contendo 20 e $23 \%$ de $\mathrm{PB}$, de forma a atender às recomendações nutricionais, exceto de potássio e cloro, segundo Rostagno et al. (2000) para aves na fase inicial.

No período de 22 a 42 dias de idade, as aves receberam uma única ração basal à base de milho, farelo de soja e glúten de milho, com $20 \%$ de PB, de modo a atender às exigências nutricionais, exceto para potássio e cloro, segundo Rostagno et al. (2000) para aves na fase de crescimento.

Essas rações foram formuladas de forma a conter $\mathrm{BE}$ de $150 \mathrm{mEq} / \mathrm{kg}$, utilizando-se como fonte de cloro o cloreto de amônia (Tabela 1).

Os valores de BE foram calculados pela seguinte fórmula, sugerida por Mongin (1981):

$$
\begin{gathered}
\mathrm{BE}=\left(\% \mathrm{Na}^{+} \times 100 / 22,990 *\right)+\left(\% \mathrm{~K}^{+} \times 100 /\right. \\
\left.39,102^{*}\right)-\left(\% \mathrm{Cl}^{-} \times 100 / 35,453^{*}\right)
\end{gathered}
$$

( ${ }^{*}$ Equivalente grama do $\mathrm{Na}^{+}, \mathrm{K}^{+}$ou $\mathrm{Cl}^{-}$, respectivamente.) 
Tabela 1 - Composições percentual e calculada das rações experimentais

Table 1 - Ingredient (\%) and calculated compositions of experimental diets

\begin{tabular}{|c|c|c|c|c|}
\hline \multirow{2}{*}{$\begin{array}{l}\text { Ingrediente } \\
\text { Ingredient }\end{array}$} & & \multicolumn{2}{|c|}{$\begin{array}{l}\text { Inicial } \\
\text { Initial }\end{array}$} & \multirow{2}{*}{$\begin{array}{l}\text { Crescimento } \\
\text { Growing } \\
\text { Ração } 20 \% \\
\text { Ration } 20 \%\end{array}$} \\
\hline & & Ração 20\% & Ração $23 \%$ & \\
\hline Milho (Corn) & & 60,870 & 55,913 & 61,785 \\
\hline Farelo de soja (Soybean meal) & & 30,128 & 28,853 & 25,582 \\
\hline Farelo de glúten de milho (Corn gluten meal) & & - & 7,941 & 4,100 \\
\hline Fosfato bicálcico (Dicalcium phosphate) & & 1,860 & 1,826 & 1,629 \\
\hline DL-metionina (99\%) (DL-methionine, $99 \%)$ & & 0,285 & 0,130 & 0,163 \\
\hline L-arginina (99\%) (L-arginine, 99\%) & & 0,097 & - & 0,153 \\
\hline Glicina (Glycine) & & 0,296 & - & - \\
\hline L-lisina $\mathrm{HCl}(98 \%)$ (L-lysine $\mathrm{HCl}, 98 \%)$ & & 0,332 & 0,295 & 0,308 \\
\hline Cloreto colina (60\%) (Choline chlorint, $60 \%)$ & & 0,100 & 0,100 & 0,100 \\
\hline Misturavitamínico ${ }^{1}$ (Vitamin supplement) & & 0,100 & 0,100 & 0,100 \\
\hline Mistura mineral ${ }^{2}$ (Mineral supplement) & & 0,050 & 0,050 & 0,050 \\
\hline Virginamicina ${ }^{3}$ (Virginiamicin) & & 0,050 & 0,050 & 0,050 \\
\hline Anticoccidiano 4 (Anticoccidiostatic) & & 0,055 & 0,055 & 0,055 \\
\hline Antioxidante $^{5}$ (Antioxidant) & & 0,010 & 0,010 & 0,010 \\
\hline Inerte (Inert) & & 1,500 & 1,500 & 1,500 \\
\hline Total & & 100,00 & 100,00 & 100,00 \\
\hline \multirow{2}{*}{\multicolumn{5}{|c|}{$\begin{array}{l}\text { Composição calculada } \\
\text { Calculated composition }\end{array}$}} \\
\hline & & & & \\
\hline Arginina digestível (Digestible arginine) & $(\%)$ & 1,260 & 1,260 & 1,178 \\
\hline Glicina + Serina (Glycine plus serine) & $(\%)$ & 2,096 & 2,096 & 1,808 \\
\hline Metionina + cistina digestível & $(\%)$ & 0,815 & 0,815 & 0,741 \\
\hline \multicolumn{5}{|l|}{ Digestible methionine + cystine } \\
\hline Lisina digestível (Digestible lysine) & $(\%)$ & 1,143 & 1,143 & 1,045 \\
\hline Treonina digestível (Digestible threonine) & $(\%)$ & 0,766 & 0,766 & 0,650 \\
\hline Triptofano digestível (Digestible tryptophan) & $(\%)$ & 0,221 & 0,221 & 0,650 \\
\hline Balanço eletrolítico (Electrolyte balance) & $(\mathrm{mEq} / \mathrm{kg})$ & 150 & 150 & 150 \\
\hline
\end{tabular}

${ }^{1}$ Rovimix (Roche) - Conteúdo (Content): vit. A, 10.000.000 UI; vit. D3, 2.000.000 UI; vit. E, 30.000 UI; vit. B1, 2,0 g; vit. B6, 4,0 g; ac. pantotênico (Pantothenic acid), 12,0 g; Biotina (Biotin), 0,10 g; vit. K3, 3,0 g; Ácido fólico (Folic acid), 1,0 g; ácido nicotínico (Nicotinic acid), $50,0 \mathrm{~g}$; vit. B12, 15.000 mcg; Selênio (Selenium), 0, $25 \mathrm{~g}$; e Veículo q. s. p., $1.000 \mathrm{~g}$.

2 Roligomix (Roche) - Conteúdo (Content): Mn, 16,0 g; Fe, 100,0 g; Zn, 100,0 g; Cu, 20,0 g; Co, 2,0 g; I, 2,0 g; e Veículo q.s.p., 1.000 g. ${ }^{3}$ Stafac $^{\circledR} 20$

${ }^{4}$ Coxistac $^{\circledR}$ - Salinomicina (Salinomicin), $12 \%$.

${ }^{5}$ Hidroxi Butil Tolueno. 
Foi utilizado delineamento experimental inteiramente casualizado, em esquema fatorial $8 \times 2$ (oito níveis de $\mathrm{BE}$ associados à duas seqüências protéicas), seis repetições e 22 aves por unidade experimental na fase inicial. Ao término desta fase, quatro aves por unidade experimental foram eliminadas para manter a uniformidade dos lotes. Na fase de crescimento, foi utilizado o mesmo delineamento experimental, mantendo-se os mesmos BE da fase inicial, por meio da suplementação à ração basal para a fase de crescimento, e 18 aves por unidade experimental. As rações basais para as fases inicial e de crescimento foram suplementadas com cloreto de amônia $\left(\mathrm{NH}_{4} \mathrm{Cl}\right)$ ou carbonato de potássio $\left(\mathrm{K}_{2} \mathrm{CO}_{3}\right)$ em substituição ao material inerte, de forma a se obter oito níveis $(0 ; 50$; $100 ; 150 ; 200 ; 250 ; 300$ e $350 \mathrm{mEq} / \mathrm{kg}$ ) de BE. As aves foram distribuídas uniformemente com um dia de idade e com peso médio de $45 \mathrm{~g}$.

$\mathrm{O}$ cloreto de amônia $\left(\mathrm{NH}_{4} \mathrm{Cl}\right)$ foi utilizado para se obter os balanços de 0,50 , e $100 \mathrm{mEq} / \mathrm{kg}$ e o carbonato de potássio $\left(\mathrm{K}_{2} \mathrm{CO}_{3}\right)$ para balanços de 200, 250, 300 e $350 \mathrm{mEq} / \mathrm{kg}$. A descrição dos tratamentos experimentais encontra-se na Tabela 2.

Aos 42 dias, após jejum alimentar de seis horas, as aves foram pesadas para a avaliação do desempenho (ganho de peso, conversão alimentar e consumo de ração). Em seguida, foram sacrificadas três aves por unidade experimental, representantes do peso médio da unidade. Após sangramento e depenação, foram evisceradas e tiveram suas carcaças (sem pés e cabeça) pesadas. Avaliou-se o peso absoluto (g) e o rendimento (\%) das carcaças evisceradas dos cortes nobres (peito, filé de peito, coxa + sobrecoxa).
$\mathrm{Na}$ determinação do rendimento de carcaça, foi considerado o peso da carcaça limpa e eviscerada, em relação ao peso vivo em jejum. Para os cortes nobres, procedeu-se à pesagem e ao cálculo dos rendimentos em relação ao peso da carcaça eviscerada.

Ao término do experimento, determinou-se o teor de umidade da cama das aves. Foram padronizados cinco pontos em todas as unidades experimentais, inserindo-se nesses pontos um tubo PVC com diâmetro de $10 \mathrm{~cm}$, coletando-se todo o material presente em seu interior e colocando-o em saco de papel, para posterior determinação do teor de matéria seca, conforme metodologia descrita por Silva (1990).

As análises estatísticas dos dados foram realizadas por intermédio do programa SAEG - Sistema para Análises Estatísticas e Genéticas (UFV, 1997). Efetuou-se análise de variância, com posterior uso de regressão polinomial para cada variável estudada em função dos níveis de BE e a verificação da significância dos coeficientes pelo teste t até $10 \%$ de probabilidade, além do teste $\mathrm{F}$, para comparação das médias dos níveis protéicos e para verificação da interação dos dos dois fatores a $5 \%$ de probabilidade.

Por interesse do estudo e considerando-se a possibilidade de ausência de interação entre os dois fatores, optou-se por estudar o do BE dentro de cada seqüência protéica e por estudar separadamente a seqüência protéica. Desse modo, o modelo estatístico utilizado foi:

$$
Y_{i j k}=m+N_{i} / P_{j}+P_{j}+e_{i j k}
$$

em que Yijk = valor observado na repetição k, do nível de balanço eletrolítico i e do nível da seqüência protéica j;

Tabela 2 - Tratamentos constituídos pelas rações basais (20 e 23\% de proteína bruta) suplementadas com $\mathrm{NH}_{4} \mathrm{Cl}$ ou $\mathrm{K}_{2} \mathrm{CO}_{3}$

Table 2 - Basal diet (20 and $23 \%$ of crude protein) supplemented with $\mathrm{NH}_{4} \mathrm{Cl}$ or $\mathrm{K}_{2} \mathrm{CO}_{3}$

\begin{tabular}{|c|c|c|c|c|c|}
\hline $\begin{array}{l}\mathrm{BE}(\mathrm{mEq} / \mathrm{kg}) \\
E B(m E q / \mathrm{kg}) \\
\end{array}$ & $\begin{array}{c}\text { Ração basal }(\mathrm{kg}) \\
\text { Basal diet }(\mathrm{kg})\end{array}$ & $\begin{array}{c}\text { Inerte }(\mathrm{kg}) \\
\text { Inert }(\mathrm{kg})\end{array}$ & $\begin{array}{l}\mathrm{NH}_{4} \mathrm{Cl}(\mathrm{kg}) \\
\mathrm{NH}_{4} \mathrm{Cl}(\mathrm{kg}) \\
\end{array}$ & $\begin{array}{c}\mathrm{K}_{2} \mathrm{CO}_{3}(\mathrm{~kg}) \\
K_{2} \mathrm{CO}_{3}(\mathrm{~kg}) \\
\end{array}$ & Total $(\mathrm{kg})$ \\
\hline 0 & 98,5 & 0,693 & 0,807 & - & 100 \\
\hline 50 & 98,5 & 0,962 & 0,538 & - & 100 \\
\hline 100 & 98,5 & 1,231 & 0,269 & - & 100 \\
\hline 150 & 98,5 & 1,500 & - & - & 100 \\
\hline 200 & 98,5 & 1,151 & - & 0,349 & 100 \\
\hline 250 & 98,5 & 0,802 & - & 0,698 & 100 \\
\hline 300 & 98,5 & 0,453 & - & 1,047 & 100 \\
\hline 350 & 98,5 & 0,104 & - & 1,396 & 100 \\
\hline
\end{tabular}

$\mathrm{BE}$ - Balanço eletrolítico (EB - Electrolyte balance).

$\mathrm{NH}_{4} \mathrm{Cl}$ - peso molecular (U.M.A.) = 53,45; pureza 99,5\% ( $\mathrm{NH}_{4} \mathrm{Cl}$ - molecular weight (U.A.M.) $=53.45$; purity 99.5\%).

$\mathrm{K}_{2} \mathrm{CO}_{3}$ - peso molecular (U.M.A.) = 138,20; pureza 99,0\% $\left(\mathrm{K}_{2} \mathrm{CO}_{3}-\right.$ molecular weight (U.A.M.) $=138.20 ;$ purity $\left.99.0 \%\right)$. 
$\mathrm{m}=$ média geral da população; $\mathrm{N}_{\mathrm{i}} / \mathrm{P}_{\mathrm{j}}=$ efeito do nível de balanço eletrolítico i ( $\mathrm{i}=0 ; 50 ; 100 ; 150 ; 200 ; 250 ; 300$; 350) dentro da seqüência protéica $\mathrm{j} ; \mathrm{P}_{\mathrm{j}}=$ efeito do nível da seqüência protéica $\mathrm{j}(\mathrm{j}=20-20 \%$ e $23-20 \%)$; $\mathrm{e}_{\mathrm{ijk}}=$ efeito do erro aleatório associado a cada observação.

\section{Resultados e Discussão}

Notou-se efeito $(\mathrm{P}<0,05)$ de balanços eletrolíticos (BE) sobre o ganho de peso e o consumo de ração dos frangos de corte para as duas seqüências protéicas estudadas (Tabela 3). Quanto à conversão alimentar, houve efeito $(\mathrm{P}<0,05)$ apenas para as aves que consumiram $23 \%$ de PB na fase inicial.

Foram observados efeitos quadráticos dos níveis de $\mathrm{BE}$ para o ganho de peso $(\mathrm{P}<0,01)$, o consumo de ração $(\mathrm{P}<0,01)$ e a conversão alimentar $(\mathrm{P}<0,05)$. Além disso, essas características apresentaram ausência de interação $(\mathrm{P}<0,05)$. Constam na Tabela 4 os valores de máximo ganho de peso e consumo de ração, além do nível ótimo de BE expresso em $\mathrm{mEq} / \mathrm{kg}$, obtidos por equações de regressão polinomiais.

O nível ótimo de BE para o ganho de peso foi de 179 e $185 \mathrm{mEq} / \mathrm{kg}$, enquanto, para o consumo de ração, os valores foram de 193 e $192 \mathrm{mEq} / \mathrm{kg}$ para as aves alimentadas com as seqüências protéicas $20-20 \%$ e 23-
$20 \%$, respectivamente. A melhor conversão alimentar correspondeu a um BE de $159 \mathrm{mEq} / \mathrm{kg}$, para as aves alimentadas com a seqüência protéica $23-20 \%$.

Esses resultados estão abaixo dos recomendados por Johnson \& Karunajeewa (1985), que, ao avaliarem dietas variando de -29 a $553 \mathrm{mEq} / \mathrm{kg}$, obtiveram um balanço de 250 a $350 \mathrm{mEq} / \mathrm{kg}$ como ótimo para o crescimento de frangos de até 42 dias de idade. Esses autores afirmaram que o BE foi prejudicial com -29 $\mathrm{mEq} / \mathrm{kg}$ da dieta, enquanto a redução do crescimento com BE maior que $300 \mathrm{mEq} / \mathrm{kg}$ era dependente do tipo de cátion $\left(\mathrm{Na}^{+}\right.$vs $\left.\mathrm{K}^{+}\right)$. O ótimo crescimento foi verificado com uma taxa $\mathrm{Na}: \mathrm{K}$ variando de 0,5 a 1,8.

As rações basais utilizadas neste trabalho possuíam relações $\mathrm{Na}: \mathrm{K}$ de 0,3 , enquanto, nas rações com $\mathrm{BE}$ de $350 \mathrm{mEq} / \mathrm{kg}$, as relações $\mathrm{Na}: \mathrm{K}$ foram de 0,11 e o teor de K foi de 1,71. Segundo Rostagno et al. (2000), o valor dessa relação é de 0,4 para frangos de corte na fase de crescimentom enquanto o NRC (1994) recomenda o valor 0,5 para a mesma fase.

Entretanto, trabalhos recentes demonstram que as mudanças no material genético e no manejo nutricional e ambiental ocasionam alterações nas exigências das aves. O NRC (1994) sugere níveis de 0,30\% de K para frangos em todas as idades. Rostagno et al. (2000) prescrevem $0,50 \%$ de $\mathrm{K}$ para aves na fase inicial e

Tabela 3 - Efeito de balanços eletrolíticos (BE) para as seqüências protéicas (20-20\% e 23-20\%) sobre o desempenho de frangos de corte de 1 a 42 dias

Table 3 - Electrolyte balances (EB) effect for protein sequences (20-20\% and 23-20\%) in broilers performance from 1 to 42 days old

\begin{tabular}{|c|c|c|c|c|c|c|}
\hline \multirow[t]{2}{*}{$\begin{array}{l}\text { Nível de BE }(\mathrm{mEq} / \mathrm{kg}) \\
\text { EB level }(m E q / \mathrm{kg})\end{array}$} & \multicolumn{2}{|c|}{$\begin{array}{c}\text { Ganho de peso }(\mathrm{g}) \\
\text { Weight gain }(\mathrm{g})\end{array}$} & \multicolumn{2}{|c|}{$\begin{array}{c}\text { Consumo de ração }(\mathrm{g}) \\
\text { Feed intake }(\mathrm{g})\end{array}$} & \multicolumn{2}{|c|}{$\begin{array}{l}\text { Conversão alimentar } \\
\text { Feed: gain ratio }\end{array}$} \\
\hline & $20-20 \%$ & $23-20 \%$ & $20-20 \%$ & $23-20 \%$ & $20-20 \%$ & $23-20 \%$ \\
\hline 00 & 2370,3 & 2320,3 & 4321,9 & 4343,9 & 1,823 & 1,872 \\
\hline 50 & 2506,7 & 2473,0 & 4578,2 & 4580,2 & 1,826 & 1,852 \\
\hline 100 & 2511,7 & 2503,9 & 4698,0 & 4650,4 & 1,870 & 1,857 \\
\hline 150 & 2583,6 & 2570,8 & 4817,2 & 4754,0 & 1,865 & 1,849 \\
\hline 200 & 2642,0 & 2575,5 & 4963,8 & 4754,1 & 1,879 & 1,846 \\
\hline 250 & 2563,9 & 2585,4 & 4720,7 & 4771,7 & 1,841 & 1,846 \\
\hline 300 & 2518,7 & 2489,2 & 4627,6 & 4581,9 & 1,837 & 1,841 \\
\hline 350 & 2370,7 & 2367,0 & 4557,4 & 4519,3 & 1,922 & 1,909 \\
\hline Média & $2508,4^{\mathrm{a}}$ & $2485,6^{\mathrm{a}}$ & $4660,6^{a}$ & $4619,4^{\mathrm{a}}$ & $1,858^{\mathrm{a}}$ & $1,859^{\mathrm{a}}$ \\
\hline Mean & & & & & & \\
\hline Efeito & $\mathrm{Q}^{* *}$ & $\mathrm{Q}^{* *}$ & $\mathrm{Q}^{* *}$ & $\mathrm{Q}^{* *}$ & ns & $\mathrm{Q}^{*}$ \\
\hline Effect & & & & & & \\
\hline CV $(\%)$ & \multicolumn{2}{|c|}{2,68} & \multicolumn{2}{|c|}{2,70} & \multicolumn{2}{|c|}{2,47} \\
\hline
\end{tabular}

$Q^{* *}$ Efeito quadrático, teste $t(P<0,01) ; Q^{*}$ efeito quadrático, teste $t(P<0,05)$; ns não-significativo; $C V$ coeficiente de variação.

$Q^{* *}$ Quadratic effect, $t$ test $(P<.01) ; Q^{*}$ Quadratic effect, $t$ test $(P<.05) ;{ }^{n s}$ not significant; $C V=$ coefficient of variation.

Médias seguidas pela mesma letra para cada característica avaliada, na linha, não diferem entre si pelo teste $F(P>0,05)$; $\mathrm{CV}=$ coeficiente de variação.

Treatments means followed by the same letter for each evaluated characteristic, in a row do not differ $(P<0.05)$ by $F$ test; $C V=c o e f f i c i e n t$ of variation. 
Tabela 4 - Equações de balanços eletrolíticos (BE) para 20 e $23 \%$ de proteína sobre o desempenho de pintos de corte de 1 a 42 dias de idade

Table 4 - Electrolyte balances (EB) equations for 20 and $23 \%$ of protein on broiler chicks performance from 1 to 42 days old

\begin{tabular}{llccc}
\hline $\begin{array}{l}\text { Característica } \\
\text { Characteristic }\end{array}$ & $\begin{array}{c}\text { Equação } \\
\text { Equation }\end{array}$ & $\mathrm{R}^{2}$ & $\begin{array}{c}\text { Máximo ponto } \\
\text { Maximum point }\end{array}$ & $\begin{array}{c}\mathrm{BE}(\mathrm{mEq} / \mathrm{kg}) \\
\text { EB }(\mathrm{mEq} / \mathrm{kg})\end{array}$ \\
\hline GP20-20\% & $\hat{\mathrm{Y}}=2365,92+2,68476 \mathrm{X}-0,00748139^{* *} \mathrm{X}^{2}$ & 0,92 & 2606,8 & 179,43 \\
GP23-20\% & $\hat{\mathrm{Y}}=2323,80+2,84505^{\#} \mathrm{X}-0,00768163^{* * *} \mathrm{X}^{2}$ & 0,96 & 2587,2 & 185,18 \\
CR20-20\% & $\hat{\mathrm{Y}}=4331,05+5,33526^{* *} \mathrm{X}-0,0138082^{* *} \mathrm{X}^{2}$ & 0,89 & 4846,4 & 193,19 \\
CR23-20\% & $\hat{\mathrm{Y}}=4361,00+4,21608^{*} \mathrm{X}-0,0109571^{* *} \mathrm{X}^{2}$ & 0,95 & 4766,6 & 192,39 \\
CA23-20\% & $\hat{\mathrm{Y}}=1,88-0,0004498 \mathrm{X}+0,0000014109^{*} \mathrm{X}^{2}$ & 0,62 & 1,84 & 159,40 \\
\hline
\end{tabular}

GP - ganho de peso (g); CR - consumo de ração $(\mathrm{g})$; CA - conversão alimentar; $\mathrm{X}$ - balanço eletrolítico; $\mathrm{BE}$ - melhor valor de balanço eletrolítico.

WG - weight gain (g); FI - feed intake (g); FG - feed:gain ratio; $X$ - electrolyte balance; $E B$ - best value of electrolyte balance.

* * Efeito significativo, teste t $(P<0,01) ;^{*}$ Efeito significativo, teste $\mathrm{t}(P<0,05)$; \# Efeito significativo, teste $\mathrm{t}(P<0,10)$.

* * Significant effect, $t$ test $(P<0.01)$; ${ }^{*}$ Significant effect, $t$ test $(P<0.05)$; \# Significant effect, $t$ test $(P<0.10)$.

$0,47 \%$, para a fase de crescimento. Oliveira (2002), por sua vez, obteve como exigências estimadas para o maior ganho de peso em frangos de corte $0,63 \%$ de $\mathrm{K}$ para o período de 8 a 21 dias de idade e $0,71 \%$ de $\mathrm{K}$ para o período de 22 a 42 dias de idade. Esses níveis, segundo o autor, corresponderam aos balanços eletrolíticos de 161 e $188 \mathrm{mEq} / \mathrm{kg}$ para os dois períodos, respectivamente.

Não houve diferença entre as médias dos tratamentos para nenhum dos parâmetros de desempenho avaliados (Tabela 3). Entretanto, o consumo de ração máximo das aves alimentadas com $23 \%$ de PB na fase inicial $(4.619,44 \mathrm{~g})$ foi numericamente inferior ao daquelas que consumiram $20 \%$ de PB na fase inicial (4660,61 g), embora a exigência de BE para o consumo de ração aos 42 dias seja considerada a mesma para os dois níveis protéicos da primeira fase (192 e $193 \mathrm{mEq} / \mathrm{kg}$ ). Isso pode ter sido resultado do nível de proteína mais elevado na fase inicial (23\%), que fez com que os aminoácidos competissem com o $\mathrm{K}$ no mecanismo de transporte ativo da bomba de $\mathrm{Na}$ e K e que o consumo na fase inicial fosse inferior com um nível protéico mais elevado na ração. Nesse sistema, quando o sódio é bombeado contra seu gradiente de concentração, potássio, aminoácidos e glicose entram na célula tanto pelo transporte ativo como por difusão passiva (Nelson \& Cox, 2000). Caso entre na célula mais potássio em restrição aos aminoácidos, estes permanecerão por maior tempo na corrente sanguínea, diminuindo o consumo de alimento, por inibir o centro da fome no hipotálamo. Possivelmente, na fase de crescimento, essa diferença no consumo se manteve na primeira semana após a mudança da ração, o que gerou esse resultado no final do período.
Constatou-se que o equilíbrio ácido-básico afetou consideravelmente a resposta produtiva das aves, de modo que aquelas que tiveram suas rações suplementadas com níveis mais altos de cloreto de amônia $(\mathrm{BE}=0$ e $50 \mathrm{mEq} / \mathrm{kg})$ apresentaram baixo desempenho, o mesmo ocorrendo com as aves cujas rações foram suplementadas com níveis elevados de carbonato de potássio ( $\mathrm{BE}=300$ e $350 \mathrm{mEq} / \mathrm{kg}$ ). Quando há excesso de K, o organismo deixa de eliminar prótons para eliminar $\mathrm{K}$, o que levaria o organismo à alcalose. A resposta fisiológica poderia ser a inibição do consumo (Granner, 1998). De outro modo, na acidose metabólica, a concentração plasmática de bicarbonato e o pH estão abaixo do normal, havendo depleção de cátions plasmáticos, como o $\mathrm{Na}$ e o $\mathrm{K} \mathrm{e}$, conseqüentemente, haveria um comprometimento do sistema da bomba de Na e K, impedindo a absorção de aminoácidos e glicose para dentro das células das aves.

Rinehart et al. (1968) demonstraram que aves alimentadas com dietas deficientes em $\mathrm{K}$ apresentaram menor nível de aminoácidos livres no plasma, mas, à medida que receberam $\mathrm{K}$, o nível de arginina $\mathrm{e}$ de lisina no plasma elevou.

Os pesos absolutos (g) e os rendimentos de carcaça e cortes nobres podem ser observados na Tabela 5. Todos os pesos absolutos apresentaram efeito quadrático, ao passo que apenas o rendimento de carcaça das aves alimentadas com $20 \%$ de PB na fase inicial foi significativo. Todas essas características estudadas apresentaram ausência de interação $(\mathrm{P}>0,05)$.

As equações de regressão polinomiais com as respectivas exigências e pontos de máximo encontram-se na Tabela 6. 
Para carcaça, os níveis ótimos de $\mathrm{BE}$ foram de 161 e $177 \mathrm{mEq} / \mathrm{kg}$, para as aves que receberam rações com 20 e $23 \%$ de PB na fase inicial, respectivamente, sendo bem próximos dos valores ótimos de BE para ganho de peso aos 42 dias. Para os demais cortes nobres, os melhores níveis de BE situaram-se em torno dessa faixa, variando de $157 \mathrm{mEq} / \mathrm{kg}$, para o peso absoluto do peito das aves alimentadas com $20 \%$ de $\mathrm{PB}$ na fase inicial, a $179 \mathrm{mEq} / \mathrm{kg}$, para o peso absoluto das pernas daquelas que consumiram $23 \%$ de PB na fase inicial.
Quanto ao rendimento de carcaça (20\% de PB na fase inicial), o BE obtido pela equação de regressão foi inferior à faixa esperada, apresentando o valor de $125 \mathrm{mEq} / \mathrm{kg}$. Entretanto, o $\mathrm{R}^{2}$ encontrado para esse parâmetro foi de 0,59 e está bem abaixo do $\mathrm{R}^{2}$ das equações de regressão dos demais parâmetros.

As características observadas estão relacionadas ao peso corporal pré-abate, sendo o peso absoluto dos cortes nobres maior para pesos corporais mais elevados. Estes resultados estão de acordo com os encontrados por Beane et al. (1979), para rendimento de

Tabela 5 - Efeito de balanços eletrolíticos (BE) para as seqüências protéicas (20-20\% e 23-20\%) sobre o peso absoluto e rendimento de carcaça de frangos de corte aos 42 dias

Table 5 - Electrolyte balances (EB) effect for protein sequences (20-20\% and 23-20\%) on weight and carcass percentage of broilers at 42 days old

\begin{tabular}{|c|c|c|c|c|c|c|c|c|}
\hline \multirow[t]{2}{*}{$\begin{array}{l}\text { Nível de } \mathrm{BE}(\mathrm{mEq} / \mathrm{kg}) \\
\text { EB level }(m E q / \mathrm{kg})\end{array}$} & \multicolumn{2}{|c|}{$\begin{array}{l}\text { Carcaça }(\mathrm{g}) \\
\text { Carcass }(g)\end{array}$} & \multicolumn{2}{|c|}{$\begin{array}{c}\text { Pernas }(\mathrm{g}) \\
\operatorname{Legs}(\mathrm{g})\end{array}$} & \multicolumn{2}{|c|}{$\begin{array}{l}\text { Peito }(\mathrm{g}) \\
\text { Breast }(g)\end{array}$} & \multicolumn{2}{|c|}{$\begin{array}{l}\text { Filé }(\mathrm{g}) \\
\text { Fillet }(\mathrm{g})\end{array}$} \\
\hline & $20-20 \%$ & $23-20 \%$ & $20-20 \%$ & $23-20 \%$ & $20-20 \%$ & $23-20 \%$ & $20-20 \%$ & $23-20 \%$ \\
\hline 0 & 1736,2 & 1716,8 & 526,2 & 526,3 & 581,5 & 577,8 & 413,3 & 427,2 \\
\hline 50 & 1874,2 & 1856,9 & 570,1 & 556,9 & 628,8 & 618,7 & 476,4 & 460,1 \\
\hline 100 & 1884,2 & 1834,8 & 572,3 & 574,8 & 635,9 & 614,7 & 472,0 & 452,6 \\
\hline 15 & 1957,3 & 1933,9 & 595,8 & 599,6 & 656,8 & 643,3 & 491,7 & 476,1 \\
\hline 200 & 1997,2 & 1945,8 & 604,0 & 599,6 & 665,0 & 644,0 & 493,5 & 473,2 \\
\hline 25 & 1803,9 & 1837,3 & 540,0 & 565,6 & 601,7 & 609,2 & 449,0 & 442,2 \\
\hline 300 & 1848,9 & 1846,6 & 566,2 & 565,5 & 612,8 & 619,8 & 457,3 & 461,3 \\
\hline 350 & 1640,3 & 1739,8 & 505,0 & 534,3 & 546,1 & 580,2 & 402,8 & 432,8 \\
\hline Média & $842,8^{a}$ & $1839,0^{\mathrm{a}}$ & $559,9^{\mathrm{a}}$ & $565,3^{a}$ & $616,1^{\mathrm{a}}$ & $613,5^{\mathrm{a}}$ & $457,0^{\mathrm{a}}$ & $453,2^{\mathrm{a}}$ \\
\hline $\begin{array}{l}\text { Mean } \\
\text { Efeito } \\
\text { Effect }\end{array}$ & $\mathrm{Q}^{* *}$ & $\mathrm{Q}^{* *}$ & $\mathrm{Q}^{* *}$ & $\mathrm{Q}^{* *}$ & $\mathrm{Q}^{* *}$ & $\mathrm{Q}^{* *}$ & $\mathrm{Q}^{* *}$ & $\mathrm{Q}^{*}$ \\
\hline CV $(\%)$ & \multicolumn{2}{|c|}{6,23} & \multicolumn{2}{|c|}{6,48} & \multicolumn{2}{|c|}{6,85} & \multicolumn{2}{|c|}{7,79} \\
\hline \multirow[t]{2}{*}{$\begin{array}{l}\text { Nível de } \mathrm{BE}(\mathrm{mEq} / \mathrm{kg}) \\
\text { EB level }(m E q / \mathrm{kg})\end{array}$} & \multicolumn{2}{|c|}{$\begin{array}{l}\text { Carcaça }(\%) \\
\text { Carcass }(\%)\end{array}$} & \multicolumn{2}{|c|}{$\begin{array}{c}\text { Pernas }(\%) \\
\operatorname{Legs}(\%)\end{array}$} & \multicolumn{2}{|c|}{$\begin{array}{l}\text { Peito (\%) } \\
\text { Breast (\%) }\end{array}$} & \multicolumn{2}{|c|}{$\begin{array}{l}\text { Filé (\%) } \\
\text { Filet (\%) }\end{array}$} \\
\hline & $20-20 \%$ & $23-20 \%$ & $20-20 \%$ & $23-20 \%$ & $20-20 \%$ & $23-20 \%$ & $20-20 \%$ & $23-20 \%$ \\
\hline 0 & 72,1 & 73,6 & 30,3 & 30,7 & 33,5 & 33,7 & 23,8 & 24,9 \\
\hline 50 & 73,1 & 74,3 & 30,4 & 30,0 & 33,5 & 33,3 & 25,4 & 24,8 \\
\hline 100 & 73,6 & 72,6 & 30,4 & 31,3 & 33,7 & 33,5 & 25,1 & 24,7 \\
\hline 150 & 73,9 & 73,5 & 30,4 & 31,0 & 33,6 & 33,3 & 25,1 & 24,6 \\
\hline 200 & 74,1 & 73,7 & 30,2 & 30,8 & 33,3 & 33,1 & 24,7 & 24,3 \\
\hline 250 & 69,5 & 70,0 & 29,9 & 30,8 & 33,4 & 33,2 & 24,9 & 24,1 \\
\hline 300 & 72,8 & 73,2 & 30,6 & 30,6 & 33,1 & 33,6 & 24,7 & 25,0 \\
\hline 350 & 68,4 & 72,5 & 30,8 & 30,7 & 33,3 & 33,3 & 24,6 & 24,9 \\
\hline Média & $72,2^{\mathrm{a}}$ & $72,9^{\mathrm{a}}$ & $30,4^{\mathrm{a}}$ & $30,7^{\mathrm{b}}$ & $33,4^{\mathrm{a}}$ & $33,4^{\mathrm{a}}$ & $24,8^{\mathrm{a}}$ & $24,6^{\mathrm{a}}$ \\
\hline $\begin{array}{l}\text { Mean } \\
\text { Efeito }\end{array}$ & $\mathrm{Q}^{* *}$ & $\mathrm{~ns}$ & $\mathrm{~ns}$ & ns & ns & $\mathrm{ns}$ & $\mathrm{ns}$ & ns \\
\hline $\begin{array}{l}\text { Effect } \\
\text { CV }(\%)\end{array}$ & & & & & & & & \\
\hline
\end{tabular}

$Q^{*}{ }^{*}$ efeito quadrático, Teste t, $(P<0,01) ; Q^{*}$ efeito quadrático, Teste $t,(P<0,05)$; ${ }^{n s}$ não-significativo; $C V=$ coeficiente de variação. $Q^{*}$ * Quadratic effect, $t$ test, $(P<0.01) ; Q^{*}$ Quadratic effect, $t$ test, $(P<0.05)$; ns not significant; $C V=$ coefficient of variation.

Médias seguidas pela mesma letra para cada característica avaliada, na linha, não diferem $(P>0,05)$ pelo teste $F$; CV $=$ coeficiente de variação.

Treatments means followed by the same letter for each evaluated characteristic, in a row do not differ $(P<0.05)$ by $F$ test; CV = coefficient of variation 
Tabela 6 - Equações de balanços eletrolíticos (BE) para 20 e $23 \%$ de proteína sobre o desempenho de pintos de corte de 1 a 42 dias de idade

Table 6 - Electrolyte balances (EB) equations for diets with 20 and $23 \%$ of protein on performance of broiler chicks from 1 to 42 days old

\begin{tabular}{lccccc}
\hline $\begin{array}{l}\text { Característica } \\
\text { Characteristic }\end{array}$ & $\begin{array}{c}\text { Seqüência protéica } \\
\text { Protein sequence }\end{array}$ & $\begin{array}{c}\text { Equação } \\
\text { Equation }\end{array}$ & $\mathrm{R}^{2}$ & $\begin{array}{c}\text { Ponto máximo } \\
\text { Maximum point }\end{array}$ & $\begin{array}{c}\mathrm{BE}(\mathrm{mEq} / \mathrm{kg}) \\
\text { EB }(\mathrm{mEq} / \mathrm{kg})\end{array}$ \\
\hline Carcaça & $20-20 \%$ & $\hat{\mathrm{Y}}=1739,42+2,66133^{\#} \mathrm{X}-0,00828294^{* *} \mathrm{X}^{2}$ & 0,83 & 1953,2 & 160,65 \\
Carcass & $23-20 \%$ & $\hat{\mathrm{Y}}=1728,87+2,12601 \mathrm{X}-0,00598691^{* *} \mathrm{X}^{2}$ & 0,83 & 1917,6 & 177,55 \\
\hline Pernas & $20-20 \%$ & $\hat{\mathrm{Y}}=529,753+0,756695 \mathrm{X}-0,00233668^{* *} \mathrm{X}^{2}$ & 0,76 & 591,0 & 161,92 \\
Legs & $23-20 \%$ & $\hat{\mathrm{Y}}=526,055+0,742542 \mathrm{X}-0,00207259^{* *} \mathrm{X}^{2}$ & 0,91 & 592,6 & 179,13 \\
\hline Peito & $20-20 \%$ & $\hat{\mathrm{Y}}=584,219+0,888780^{\#} \mathrm{X}-0,00282699^{* * *} \mathrm{X}^{2}$ & 0,87 & 654,1 & 157,19 \\
Breast & $23-20 \%$ & $\hat{\mathrm{Y}}=581,389+0,637662 \mathrm{X}-0,00181755^{* *} \mathrm{X}^{2}$ & 0,81 & 637,3 & 175,42 \\
\hline Filé & $20-20 \%$ & $\hat{\mathrm{Y}}=423,366+0,812792 \mathrm{X}-0,00248298^{* *} \mathrm{X}^{2}$ & 0,81 & 489,9 & 163,67 \\
Fillet & $23-20 \%$ & $\hat{\mathrm{Y}}=432,351+0,410434 \mathrm{X}-0,00116506^{*} \mathrm{X}^{2}$ & 0,63 & 468,5 & 176,14 \\
\hline \% Carcaça & $20-20 \%$ & $\hat{\mathrm{Y}}=72,1998+0,023376^{\#} \mathrm{X}-0,000093428^{\#} \mathrm{X}^{2}$ & 0,59 & 73,7 & 125,10 \\
$\%$ Carcass & & & & & \\
\hline
\end{tabular}

\% - Rendimento de carcaça; cortes nobres das aves: pernas, peito e filé; $\mathrm{X}$ - balanço eletrolítico; EB - melhor valor de balanço eletrolítico.

$\%$ - Carcass yield; poultry noble cuts: legs, breast and fillet; $X$ - eletrolyte balance; $E B$ - best value of electrolyte balance.

* * Efeito significativo, teste t $(P<0,01) ;{ }^{*}$ Efeito significativo, teste $t(P<0,05)$; \# Efeito significativo, teste $t(P<0,10)$.

* * Significant effect, $t$ test $(P<0.01)$; ${ }^{*}$ Significant effect, $t$ test $(P<0.05)$; $\#$ Significant effect, $t$ test $(P<0.10)$.

carcaça; Rosa et al. (1994), para perna e peito com osso; e Palo et al. (1992), para músculo peitoral. Divergem, porém, dos obtidos por Scheideler \& Baughman (1993), para rendimento de carcaça, e Sizemore \& Barbato (1992), para músculo peitoral.

Observou-se que BE altos e baixos foram os responsáveis pelo aumento na umidade da cama das aves (Tabela 7). Todas as características estudadas apresentaram ausência de interação $(\mathrm{P}>0,05)$. Foram observados efeitos quadráticos $(\mathrm{P}<0,01)$ tanto para a ração com $20 \%$ de PB na fase inicial quanto para a ração com $23 \%$ de PB nessa mesma fase (Tabela 8). Não houve interação $(\mathrm{P}>0,05)$ do $\mathrm{BE}$ com as seqüências protéicas para o teor de matéria seca na cama das aves.

Os ótimos valores de BE podem ser verificados na Tabela 8 e foram de 138 e $147 \mathrm{mEq} / \mathrm{kg}$, correspondendo a 73,83 e $73,43 \%$ de matéria seca na cama de frango para os tratamentos em que as aves consumiram rações com 20 e $23 \%$ de PB na fase inicial, respectivamente.

Esses dados corroboram os obtidos por Hijikuro (1976), citado por Casado \& Viserda (1983), que, trabalhando com aves de recria e suplementando as rações com diferentes níveis de cloreto de sódio, observou que, à medida que o consumo de sal elevou, houve aumento do consumo de água e de produção de "urina".
Tabela 7 - Efeitos de balanços eletrolíticos (BE) para as seqüências protéicas (20-20\% e 23-20\%) sobre a matéria seca (\%) da cama de frangos de corte de 1 a 42 dias de idade

Table 7 - Effects of electrolyte balances (EB) for the protein sequences $(20-20 \%$ and $23-20 \%)$ on the litter dry matter of broilers from 1 to 21 days old

\begin{tabular}{|c|c|c|}
\hline \multirow{2}{*}{$\begin{array}{l}\text { Níveis de BE } \\
(\mathrm{mEq} / \mathrm{kg}) \\
\text { EB levels }\end{array}$} & \multicolumn{2}{|c|}{$\begin{array}{c}\text { Matéria seca da cama (\%) } \\
\text { Dry matter of the broiler litter }(\%)\end{array}$} \\
\hline & $20-20 \%$ & $23-20 \%$ \\
\hline 00 & 66,1 & 62,9 \\
\hline 50 & 67,6 & 69,8 \\
\hline 100 & 73,0 & 72,5 \\
\hline 150 & 75,0 & 75,5 \\
\hline 200 & 72,9 & 71,7 \\
\hline 250 & 68,4 & 68,1 \\
\hline 300 & 59,1 & 60,6 \\
\hline 350 & 53,5 & 57,4 \\
\hline Média & $67,0^{\mathrm{a}}$ & $67,3^{\mathrm{a}}$ \\
\hline Efeito & $Q^{* *}$ & $\mathrm{Q}^{* *}$ \\
\hline CV $(\%)$ & 4,34 & \\
\hline
\end{tabular}

$Q^{*}$ * efeito quadrático, teste $t(P<0,01) ; Q^{*}$ efeito quadrático, teste $t \quad(P<0,05) ;$ ns não-significativo; $C V=$ coeficiente de variação.

$Q^{* *}$ Quadratic effect, $t$ test $(P<.01) ; Q^{*}$ Quadratic effect, $t$ test $(P<.05)$; ns not significant; CV = coefficient of variation.

Médias seguidas pela mesma letra para cada característica avaliada, na linha, não diferem entre si pelo teste $F(P>0,05)$; $\mathrm{CV}=$ coeficiente de variação.

Treatment means followed by the same letter for each evaluated characteristic, in a row do not differ $(P<0.05)$ by $F$ test; $C V=$ coefficient of variation. 
Tabela 8 - Equações de balanços eletrolíticos (BE) para 20 e 23\% de proteína sobre o teor de matéria seca na cama das aves aos 42 dias de idade

Table 8 - Electrolyte balances (EB) equations for diets with 20 and $23 \%$ of protein on the litter dry matter of broilers at 42 days old

\begin{tabular}{lcccc}
\hline $\begin{array}{l}\text { Característica } \\
\text { Characteristic }\end{array}$ & $\begin{array}{c}\text { Equação } \\
\text { Equation }\end{array}$ & $\mathrm{R}^{2}$ & $\begin{array}{c}\text { Máximo ponto } \\
\text { Maximum point }\end{array}$ & $\begin{array}{c}\mathrm{BE}(\mathrm{mEq} / \mathrm{kg}) \\
\text { EB }(\mathrm{mEq} / \mathrm{kg})\end{array}$ \\
\hline $\begin{array}{l}\text { \% MS 20-20\% } \\
\% D M ~ 20-20 \%\end{array}$ & $\hat{\mathrm{Y}}=64,77+0,13117^{* *} \mathrm{X}-0,000474635^{* *} \mathrm{X}^{2}$ & 0,95 & 73,83 & 138,17 \\
$\% \mathrm{MS} \mathrm{20-23 \%}$ & $\hat{\mathrm{Y}}=63,84+0,13003^{* *} \mathrm{X}-0,000440715^{* *} \mathrm{X}^{2}$ & 0,94 & 73,43 & 147,52 \\
$\% D M 23-20 \%$ & & & & \\
\hline
\end{tabular}

\% MS - porcentagem de matéria seca; $X$ - balanço eletrolítico; BE - melhor valor de balanço eletrolítico.

$\%$ DM - percentage of dry matter; $X$ - eletrolyte balance; $E B$ - best value of electrolyte balance.

E* Efeito significativo, teste $t(P<0,01)$

* Significant effect, $t$ test $(P<0.01)$

Tanto o aumento de $\mathrm{K}$ quanto o de $\mathrm{Cl}$ foram suficientes isoladamente para o aumento de umidade na cama das aves deste trabalho, o que está de acordo com o observado por Day (1986), que também observou aumento de consumo e de excreção de água com aumento dos níveis de $\mathrm{Na}(0,1$ para $0,2 \%)$ e potássio $(0,6$ para $0,9 \%)$ na ração de frangos. Porém, o autor não observou alteração no consumo e na excreção de água quando elevou o nível de $\mathrm{Cl}(0,10$ para $0,25 \%)$. Entretanto, ressalta-se que, mesmo após aumentar o nível de $\mathrm{Cl}$, este ainda se encontrava abaixo das exigências descritas na por Rostagno (2000) e da recomendação de Oliveira (2002), mas dentro do nível preconizado pelo NRC (1994).

Esses resultados também estão de acordo com os relatados por Oliveira (2002), ao verificar que o consumo de água das aves foi afetado pelo nível de $\mathrm{K}$ da dieta, concluindo que as excretas das aves que consumiram pouco ou muito $\mathrm{K}$ apresentaram menor conteúdo de matéria seca na cama, o que reforça os dados obtidos por Rinehart et al. (1969), que constataram que aves alimentadas com rações deficientes em $\mathrm{K}$ consumiram e excretaram mais água que as que receberam nível adequado desse nutriente. Para os autores, esse comportamento estava associado ao apetite depravado, à apatia e à hipotensão.

\section{Conclusões}

Os ótimos BE estimados para os parâmetros de desempenho variaram de 159 a $195 \mathrm{mEq} / \mathrm{kg}$ e os maiores teores de matéria seca na cama dos frangos corresponderam aos valores de BE de 138 e 147 mEq/kg para as aves que receberam as seqüências protéicas $20-20 \%$ e $23-20 \%$ de PB, respectivamente. Para o rendimento de carcaça e dos cortes nobres, os melhores valores de $\mathrm{BE}$ encontrados foram similares aos de desempenho, recomendando-se, portanto, um valor de BE na faixa de 160 a $190 \mathrm{mEq} / \mathrm{kg}$ como ótimo para frangos de corte de 1 a 42 dias de idade.

\section{Literatura Citada}

BEANE, W.L.; CHERRY, J.A.; WEAVERW JR., W.D Intermittent light and restricted feeding broiler chickens. Poultry Science, v.58, p.567-571, 1979

CASADO, E.S.; VIRSEDA, T.A. Influencia e los minerales y otros nutrientes sobre la humedad de las deyecciones de los broilers, In: SIMPOSIUM DE LA SECCIÓN ESPÑOLA DE LA WPSA, 21., 1983, Barcelona. Anais... Barcelona: 1983.

DAY, E.J. Interation of coccidiostats with nutrients. San Diego: Academic Press, 1986. 32p.

GRANNER, K.D. Hormônios da córtex da adrenal. In: HARPER, J.C (Ed.) Bioquímica. 8.ed. São Paulo: Atheneu, 1998. p.707-709.

HALLEY, J.T.; NELSON, T.S.; KIRBY, L.K. et al. Effect of altering dietary mineral balance on growth, leg abnormalities, and blood base excess in broiler chicks. Poultry Science, v.66, p.1684-1692, 1987.

JOHNSON, R.J.; KARUNAJEEWA, H. The effects of dietary minerals and electrolytes on the growth and physiology of the young chick. Journal Nutrition, v.115, p.1680-1690, 1985.

LEESON, S.; SUMMERS, J.D. Scott's nutrition of the chicken. 4.ed. Ontario: University Books, 2001. 591p.

MONGIN, P. Recent advances in dietary anion-cation balance: application in poultry. Procedure Nutrition Society, v.40, p.285-294, 1981

MURAKAMI, A.E. Balanço eletrolítico da dieta e sua influência sobre o desenvolvimento dos ossos de frangos. In: CONFERÊNCIA APINCO DE CIÊNCIA E TECNOLOGIA AVÍCOLAS, 2000, Campinas. Palestras... Campinas: Fundação APINCO de Ciência e Tecnologia Avícolas, 2000. p.33-61.

NELSON, D.L.; COX, M.M. Biological membranes and transport. In: NELSON, D.L.; COX, M.M. (Eds.) Lehninger principales of biochemistry. 3.ed. New York: Worth Publishers, 2000. p.389-436.

NATIONAL RESEARCH COUNCIL - NRC. Nutrient requirements of poultry. 9.ed. Washington, D.C.: National Academy Press, 1994. 155p

OLIVEIRA, J.E. Exigência nutricional de potássio para frangos de corte. Viçosa, MG: Universidade Federal de Viçosa, 2002. 64p. Dissertação (Mestrado em Zootecnia) - Universidade Federal de Viçosa, 2002. 
PALO, P.E.; SELL, J.L. et al. Effects of early nutrient restriction on select characteristics of the gastrointestinal tract and performance of broiler chickens. Poultry Science, v.71, p.112, 1992.

RINEHART, K.E.; FEATHERSTON, W.R.; ROGLER, J.C. Effects of a dietary potassium deficiency on protein synthesis in the young chick. Journal of Nutrition, v.95, n.4, p.627632, 1968.

RINEHART, K.E.; FEATHERSTON, W.R.; ROGLER, J.C. Influence of dietary potassium on chick growth, food consumption and blood and tissue composition. Poultry Science, v.48, p.320-325, 1969.

ROSA, P.S.; FONSECA, J.B.; HOSTAGNO, H.S. et al. Desempenho e qualidade de carcaça de frangos submetidos a diferentes programas de restrição alimentar. In: CONFERÊNCIA APINCO DE CIÊNCIA E TECNOLOGIA AVÍCOLAS, 1994, Santos. Anais... Campinas: Fundação APINCO de Ciência e Tecnologia Avícolas, 1994. p.15-16.
ROSTAGNO, H.S. Tabelas brasileiras para aves e suínos: Composição de alimentos e exigências nutricionais. Viçosa, MG: Universidade Federal de Viçosa, 2000. 141p.

SCHEIDELER, S.; BAUGHMAN, G.R. Computerized early feed restriction programs for various strains of broilers. Poultry Science, v.72, p.236-242, 1993.

SILVA, D.J. Análises de alimentos: métodos químicos e biológicos. 2.ed. Viçosa, MG: Universidade Federal de Viçosa, 1990. 165p.

SIZEMORE, F.G.; BARBATO, G.F. Effect of feed restriction at different ages in chickens selected fog high 14 or 42 day exponential growth rate. Poultry Science, v.71, 1992.

Recebido em: 16/02/04

Aceito em: 14/06/05 